\title{
Designing of bolero jackets with abstract motifs
}

\author{
Deepti Bhargava and Akansha Balyan
}

Received: 14.02.2020; Revised: 10.11.2020; Accepted: 28.11 .2020

See end of the paper for authors' affiliations Deepti Bhargava Department of Home Science, Banasthali Vidyapeeth, Banasthali (Rajasthan) India Email : bhargava.deepti95@ gmail.com
ABSTRACT : The present study was undertaken by the investigator to add a new range and interesting ideas which can break monotony and give a touch of novelty in designing of bolero jackets using abstract motifs.Bolero jackets contribute to create a variety of styles which can provide a different look with fashion needs. Thirty abstract motifs were collected and best 5 motifs were selected for the designing of bolero jackets. Various types of designs were prepared using different features for bolero jackets. Finally, five designs were selected to construct prototypes on the basis of consumer preferences.Selected motifs were digitally printed on bolero jackets. Then prototypes were constructed and evaluated. Developed garments were successful to achieve the objectives of the study. All prototypes were liked by the respondents. Thus, the designing of bolero jackets was found very creative and useful for consumers.Present study has fulfilled its objectives with high performance of appreciation.

KEY WORDS: Bolero jackets, Abstract motifs, Digital printing, Garment designing

- HOW TO CITE THIS PAPER : Bhargava, Deepti and Balyan, Akansha (2020). Designing of bolero jackets with abstract motifs. Asian J. Home Sci., 15 (2) : 404-408, DOI: 10.15740/HAS/AJHS/15.2/404408. Copyright@2020: Hind Agri-Horticultural Society. 